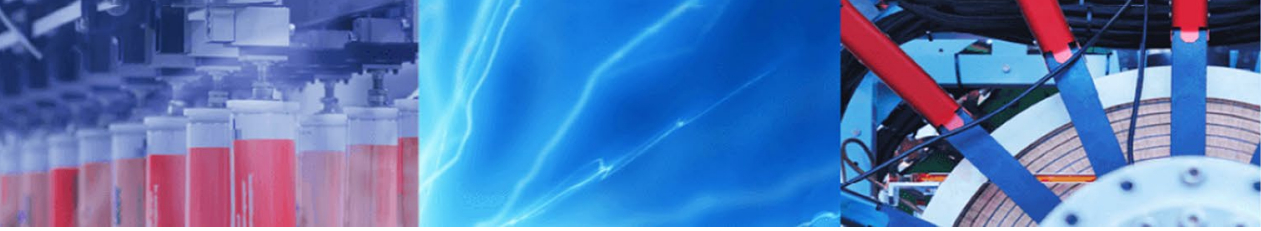

Research Article

\title{
Optimization of biodiesel production from high free fatty acid river catfish oil (Pangasius hypothalamus) and waste cooking oil catalyzed by waste chicken egg shells derived catalyst
}

\author{
Gopalan Santya ${ }^{1} \cdot$ Thevaraju Maheswaran $^{1} \cdot$ Kian Fei Yee $^{1}$ (1)
}

C Springer Nature Switzerland AG 2019

\begin{abstract}
The present study investigated the suitability of the river catfish oil (RCFO) and waste cooking oil (WCO) in transesterification reaction, catalyzed by chicken egg shells derived catalyst. Besides that, a process optimization study was conducted to reveal the effect of molar ratio of oil to methanol and catalyst loading on the yield of fatty acid methyl esters (FAME). RCFO was extracted from river catfish waste with the recovery of oil of $17.39 \mathrm{wt} \%$. An esterification reaction was carried out prior to transesterification reaction, due to the high percentage of free fatty acid (FFA\%) in RCFO (4.93\%) and WCO $(11.28 \%)$. The FFA\% was reduced to less than $1 \%$ under the optimized parameters of volume percentage of sulfuric acid to oil of $0.5 \% \mathrm{v} / \mathrm{v}$ and volume percentage of methanol to oil of $45 \% \mathrm{v} / \mathrm{v}$ at $60^{\circ} \mathrm{C}$ for $2 \mathrm{~h}$. Transesterification results showed that an optimum yield of FAME of $87.77 \%$ for RCFO and $96.23 \%$ for WCO were obtained under the same optimum conditions of 1:12 of molar ratio of oil to methanol, $1.5 \mathrm{wt} \%$ of catalyst loading, $60 \mathrm{~min}$ and $60^{\circ} \mathrm{C}$. The chicken egg shells derived catalyst exhibited high catalytic activity due to the high specific surface area of $5.2090 \mathrm{~m}^{2} / \mathrm{g}$. The physiochemical properties of RCFO biodiesel and WCO biodiesel were characterized and it indeed met the biodiesel standard of ASTM D6751. Hence, both RCFO and WCO were feasible to use as the feedstocks in biodiesel production.
\end{abstract}

Keywords River catfish oil · Waste cooking oil · Chicken egg shells derived catalyst · Biodiesel · Optimization

\section{Introduction}

The fluctuation in the price of crude oil and the increase of noxious waste emissions caused by the combustion of fossil fuels have brought into the need for developing an alternative fuels which could create less pollution and more eco-friendly. Biodiesel or also known as fatty acid alkyl ester which is product from transesterification of animal fats or vegetable oils with alcohol happens to have high potential to be a substitute for petroleum-based fuels [1]. Fatty acid methyl esters (FAME) is a well-known biodegradable and renewable energy source to help meet the increasing shortages of petro-diesel whilst providing economic and environmental benefits [2]. Besides that, the utilization of biodiesel in engine is one of the green way in the reduction of particular matter, carbon monoxide as well as the unburnt hydrocarbon [3]. Hence, it would eventually play a role in reducing the global warming.

Waste feedstocks such as waste oils, fish waste, waste egg shells and rendered animal fats are the possible source of feedstocks in biodiesel production. Fish oil extracted from fish waste is one of the potential renewable and non-edible feedstock in biofuel production in which the issue of food versus fuel can be avoided. Generally, fish oil contains a small percentage of polyunsaturated fatty acids such as linoleic acid and linolenic acid, as compared to vegetable oil. In other words, fish oil has a high percentage of saturated fatty acid which resulted it is more stable and less vulnerable to rancidity than vegetable oil. Apart from that, fish oil derived biofuel has higher cetane number

Kian Fei Yee, kianfei.yee@miu.edu.my | ${ }^{1}$ Department of Chemical Engineering, School of Science and Engineering, Manipal International University, Putra Nilai, Negeri Sembilan Darul Khusus 71800, Malaysia.

SN Applied Sciences (2019) 1:152 | https://doi.org/10.1007/s42452-018-0155-z

Received: 14 October 2018 / Accepted: 28 December 2018 / Published online: 7 January 2019

SN Applied Sciences

a SPRINGer Nature journal 
compared to vegetable oil derived biofuel, in which higher cetane number is known to have lower exhaust gas emission due to the fuel has longer combustion time in engines $[4,5]$. Therefore, fish oil derived biofuel is comparatively better than vegetable oil derived biofuel in reducing the environment pollution.

Pangasius hypothalamus, so called river catfish is one of the major fish species in Vietnamese aquaculture, whereas Thailand, Malaysia, Indonesia, Cambodia, Bangladesh and China are also the main producer countries [6]. The fish are sold as live whole fish in the domestic market and as frozen fish fillets exported to other countries such as Australia. However, the non-edible parts of the fish such as skin, viscera, dorsal fins, tail and liver are discarded on land or hauled into ocean as waste [7]. In this study, the production of biodiesel from waste materials such as river catfish oil (RCFO) and waste cooking oil (WCO) were investigated, by using waste eggs shell derived catalyst. The oils were pretreated before carrying out transesterification. The effect of catalyst loading and oil to methanol molar ratio were studied for maximum yield of FAME through onefactor-at-a-time (OFAT) approach.

\section{Materials and methods}

\subsection{Materials}

The oil feedstocks, River catfish waste (RCFW) was collected from a local market in Malaysia. The WCO and waste chicken egg shells were collected from a restaurant in Malaysia. Methanol (99.8\%), sodium chloride ( $\geq 99.9 \%)$ and ethyl alcohol absolute $(\geq 95.6 \%)$ were purchased from Chem Solution, Malaysia. Hydrochloric acid (37\%), sulfuric acid (95-98\%), diethyl ether ( $\geq 99.5 \%$ ) and methyl heptadecanoate $(\geq 99 \%)$ were purchased from R\&M Chemicals, Malaysia. Petroleum ether ( $\geq 95 \%)$ and potassium hydroxide ( $\geq 85 \%$ ) were purchased from Bendosen, Malaysia. All the chemicals used were analytical reagent grade.

\subsection{Methods}

\subsubsection{RCFO extraction and purification}

The collected RCFW were washed and cleaned to remove the blood stains which then was grinded using a blender. The RCFW stock then boiled with distilled water in a $1000 \mathrm{ml}$ beaker with heat source from hot plate at $80-100{ }^{\circ} \mathrm{C}$ for $30-45 \mathrm{~min}$ or until the oil particles formed at top layer. The boiled broth was then left to cool and filtered through a cloth filter to remove the fish excess. Then, sodium chloride was added into the RCFO to remove excess moisture and finally the RCFO was filtered again to remove sodium chloride particles. The percentage of oil recovery was calculated using Eq. 1 [8].

Percentage of oil recovery (\% )

$$
=\frac{\text { Weight of the extracted RCFO }(\mathrm{g})}{\text { Weight of RCFW }(\mathrm{g})} \times 100 \%
$$

\subsubsection{Calcination of chicken egg shells}

The chicken egg shells were rinsed with distilled water to remove the deposited impurities. Then the washed chicken egg shells were placed under hot sun for drying purpose. The dried chicken egg shells were grinded using a blender and sieved to powder form of $150 \mu \mathrm{m}$. The powdered chicken egg shells then heated in $900^{\circ} \mathrm{C}$ in a muffle furnace for $1 \mathrm{~h}$ under static air conditions. The calcined sample were kept in a closed vessel to avoid humidity in air.

\subsubsection{Characterization of chicken egg shells derived catalyst}

Scanning electron microscopy (SEM) analysis was performed to study the morphology of the egg shells derived catalyst by using a high resolution scanning electron microscope. The specific surface areas of the egg shells derived catalyst was determined by BET analysis using a Micromeritics ASAP2020 surface area and porosity analyzer. Nitrogen adsorption measurements were performed at $-196{ }^{\circ} \mathrm{C}$ and the specific surface area of the catalyst were determined from adsorption isotherms using the Brunauer-Emmett-Teller (BET) method.

\subsubsection{Acid esterification study}

$100 \mathrm{ml}$ of oil was poured into a three-neck round bottom flask connected to a condenser and preheated in a water bath at $60{ }^{\circ} \mathrm{C} .30 \% \mathrm{v} / \mathrm{v}$ methanol to oil and $0.5 \% \mathrm{v} / \mathrm{v}$ sulfuric acid to oil were added to the preheated oil, respectively. The mixture was constantly stirred with magnetic stirrer at $300 \mathrm{rpm}$ and $60^{\circ} \mathrm{C}$ were kept for $120 \mathrm{~min}$ under atmospheric pressure. After the completion of the reaction, the mixture was transferred to a $1000 \mathrm{ml}$ separation funnel to separate the excess alcohol, impurities and sulfuric acid into two layers. The excess alcohol, sulfuric acid and impurities were at the top layer which was discarded. The lower layer was then analyzed to measure the percentage of free fatty acid (FFA\%). The steps were repeated by varying the methanol to oil volume percentage of $40 \% \mathrm{v} / \mathrm{v}$ and $45 \% \mathrm{v} / \mathrm{v}$ and also varying sulfuric acid to oil volume percentage to $1 \% \mathrm{v} / \mathrm{v}$ to obtain optimum conversion of the oil with the least in FFA\% of less 
than $1 \%$. The conversion efficiency of RCFO and WCO in the acid esterification reaction was calculated using Eq. 2 [9].

Conversion efficiency (\%)

$$
=\frac{\text { Initial acid value }- \text { Final acid value }}{\text { Initial acid value }} \times 100 \%
$$

\subsubsection{Alkaline transesterification study}

$50 \mathrm{ml}$ of esterified oil and oil to methanol molar ratio of 1:6 were added into a three-neck round bottom flask which connected with a condenser. The resulted mixture was preheated to $60^{\circ} \mathrm{C}$. Then, a catalyst loading of $1.5 \mathrm{wt} \%$ of chicken egg shells derived catalyst $(\mathrm{CaO})$ was weighed and mixed with the reactants. The mixture was constantly heated at $60{ }^{\circ} \mathrm{C}$ and stirred at $400 \mathrm{rpm}$ for $60 \mathrm{~min}$. After that, the mixture was transferred to a $250 \mathrm{ml}$ separation funnel to allow two layer separation. The impure biodiesel remained in upper layer whereas the lower layer contained glycerol. The steps mentioned above were repeated for oil to methanol molar ratio of 1:9, 1:12, and 1:15 and catalyst loading of $1 \mathrm{wt} \%, 1.5 \mathrm{wt} \%, 2 \mathrm{wt} \%$ and $2.5 \mathrm{wt} \%$.

\subsubsection{Characterization of RCFO, WCO and FAME}

The properties of RCFO, WCO and FAME including density $\left(\mathrm{kg} / \mathrm{m}^{3}\right)$, saponification value $(\mathrm{mg} \mathrm{KOH} / \mathrm{g})$, acid value ( $\mathrm{mg} \mathrm{KOH} / \mathrm{g})$, FFA\%, kinematic viscosity $\left(\mathrm{mm}^{2} / \mathrm{s}\right)$ and calorific value $(\mathrm{MJ} / \mathrm{kg})$ were analyzed [10-13]. The average molecular weight of RCFO and WCO were calculated using Eq. 3 [12], where SV and AV were the saponification value and acid value, respectively.

Molecular weight of oil $(\mathrm{kg} / \mathrm{mol})=\frac{168300}{S V-A V}$
Besides that, gas chromatography-mass spectrometry (GC-MS) was performed on the RCFO, WCO and reaction samples using an Agilent 7890A gas chromatograph coupled with a mass spectrometer system (MS) of an Agilent $5975 C$ inert MSD with triple-axis detector. The length and diameter of column were $30 \mathrm{~m}$ and $0.25 \mathrm{~mm}$, respectively. The stationary phase used was $5 \%$ phenyl methylpolysiloxane and methyl heptadecanoate was used as internal standard (IS) for the calculation of biodiesel yield. A quantity of $3 \mu \mathrm{L}$ from each samples was injected in the GC-MS. The GC/MSD Chemstation software and NIST/EPA/ $\mathrm{NIH}$ version 2.0 were used to identify the peaks in the GC chromatogram. The yield of biodiesel was calculated by using Eq. 4, as a summation of total weight of biodiesel produced to the weight of oil used, multiplied by 100. [14].

Yield of biodiesel $(\%)=\frac{\sum \text { Weight of FAME }(\mathrm{g})}{\text { Weight of oil used }(\mathrm{g})} \times 100 \%$

\section{Results and discussion}

\subsection{Physical and chemical properties of RCFO and WCO}

Fatty acids compositions of RCFO and WCO were shown in Table 1. It was observed that RCFO contains a higher percentage of saturated fatty acid (SFA) which was $45.31 \%$, compared to $22.87 \%$ for WCO. SFA is known as having close packing of saturated fat molecules which makes it solidify at room temperature whereas monounsaturated fatty acid (MUFA) and polyunsaturated fatty acid (PUFA) keeps the oil liquid at room temperature which practically lowers the gel point [15]. This defines the reason why the RCFO was in semi-solid state at room temperature. The fatty acid compositions of RCFO and WCO were in
Table 1 Fatty acid composition of RCFO and WCO in comparison with the reported findings

\begin{tabular}{lllll}
\hline Fatty acid compositions (\%) & $\begin{array}{l}\text { RCFO (\%) } \\
\text { (this study) }\end{array}$ & RCFO (\%) [16] & $\begin{array}{l}\text { WCO (\%) } \\
\text { (this study) }\end{array}$ & WCO (\%) [17] \\
\hline Myristic acid, C14:0 & 3.04 & - & - & - \\
Palmitic acid, C16:0 & 26.32 & 33.73 & 18.14 & 13.62 \\
Stearic acid, C18:0 & 15.95 & 9.70 & 4.73 & 4.14 \\
Total saturated fatty acid (\%) & 45.31 & 43.43 & 22.87 & 17.76 \\
Palmitoleic acid, C16:1 & 6.56 & 4.03 & - & - \\
Oleic acid, C18:1n9c & 33.98 & 36.10 & 38.86 & 33.75 \\
Total monounsaturated fatty acid (\%) & 40.53 & 40.13 & 38.86 & 33.75 \\
Linoleic acid, C18:3n3 & 9.64 & 0.29 & 36.45 & 43.85 \\
Linolenic acid, C18:3 & - & 4.39 & 1.82 & 4.65 \\
Arachidonic acid, C20:4n6 & 1.09 & 1.92 & - & - \\
Eicosapentaenoic acid (EPA), C20:5n3 & 0.71 & 1.00 & - & - \\
Docosahexaenoic acid (DHA), C22:6n3 & 2.79 & - & - & - \\
Total polyunsaturated fatty acid (\%) & 14.22 & 7.6 & 38.27 & 48.5 \\
\hline
\end{tabular}


accordance with the findings reported by Muhamad and Mohamad [16] and Abidin et al. [17]. Apart from the fatty acids, Table 2 revealed that RCFO and WCO contained a high acid value of $9.81 \mathrm{mg} \mathrm{KOH} / \mathrm{g}$ and $22.4 \mathrm{mg} \mathrm{KOH} / \mathrm{g}$, respectively due to the significant amount of fatty acid oxidation products such as alkenes in the oils. On the other hand, the rotten smell of oils was due to the appearance of ketones such as 2-pentanone, dodecane, $(E)$-hex2-enal and (E)-dec-2-enal in the oils [18]. The saponification value of $196.35 \mathrm{mg} / \mathrm{g}$ for RCFO and $213.01 \mathrm{mg} / \mathrm{g}$ for WCO indicated the high concentration of triglycerides in the oils that were suitable used as feedstocks in the production of biodiesel [19]. In this study, $17.39 \mathrm{wt} \%$ of RCFO was successfully recovered through oil extraction of RCFW.

\subsection{Acid esterification}

RCFO and WCO containing high FFA\% which was $4.93 \%$ and $11.28 \%$ respectively, as shown in Table 2 . Therefore, it was necessary to carry out the esterification process to reduce the FFA\% to less than $1 \%$. The FFA\% must be lower than $1 \%$ in the oils before transesterification because every $1 \%$ of FFA produces approximately $1.11 \%$ soaps under alkaline conditions which are nearly impossible to remove [20].

\subsubsection{Effect of volume percentage of methanol to oil on FFA\%}

The effect of volume percentage of methanol to oil on the FFA\% and conversion efficiency was shown in Fig. 1. Generally, the results revealed that the FFA\% decreased as the volume percentage of methanol to oil increased, for both
Table 2 Physical and chemical properties of RCFO and WCO
Fig. 1 Effect of volume percentage of methanol to oil on FFA $\%$ and conversion efficiency (reaction temperature of $60^{\circ} \mathrm{C}$, reaction time of $2 \mathrm{~h}$, volume percentage of sulfuric acid to oil of $0.5 \% \mathrm{v} / \mathrm{v}$ )

\begin{tabular}{llll}
\hline Property & Unit & RCFO & WCO \\
\hline Color & - & Cloudy yellow @ 27 ${ }^{\circ} \mathrm{C}$ & Dark brown \\
& & Clear yellow @ 60 ${ }^{\circ} \mathrm{C}$ & \\
Odor & - & Rotten smell & Rotten smell \\
Physical state @ $27^{\circ} \mathrm{C}$ & - & Semi-solid & Liquid \\
Acid value & $\mathrm{mg} \mathrm{KOH} / \mathrm{g}$ & 9.81 & 22.44 \\
Calorific value & $\mathrm{MJ} / \mathrm{kg}$ & 36.32 & 23.60 \\
Density & $\mathrm{kg} / \mathrm{m}^{3}$ & 869.6 & 880.1 \\
FFA & $\%$ & 4.93 & 11.28 \\
Kinematic viscosity @ $40^{\circ} \mathrm{C}$ & $\mathrm{mm} / \mathrm{s}$ & 43.60 & 35.41 \\
Molecular weight & $\mathrm{g} / \mathrm{mol}$ & 902.22 & 883.14 \\
Saponification value & $\mathrm{mg} \mathrm{KOH} / \mathrm{g}$ & 196.35 & 213.01 \\
Oil recovery from RCFW & $\mathrm{wt} \%$ & 17.39 & - \\
\hline
\end{tabular}

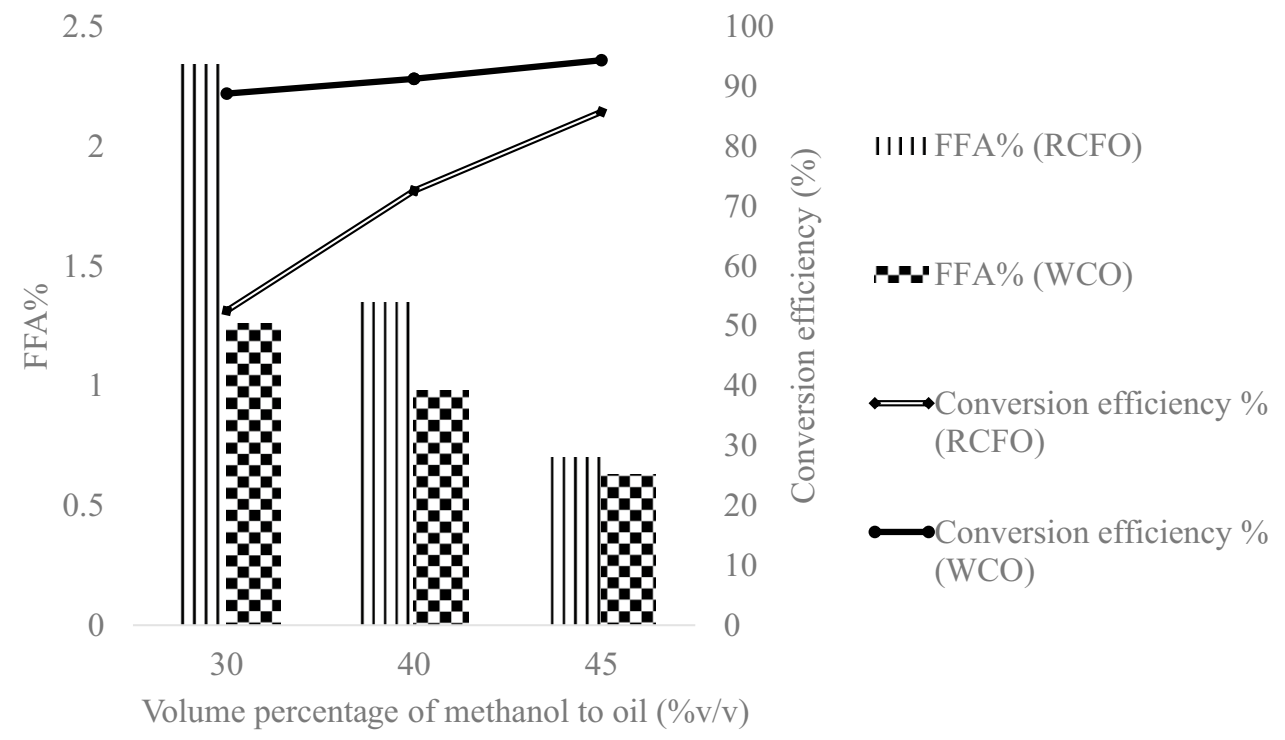


RCFO and WCO. This phenomenon was due to the interaction between FFA in the oil and methanol was enhanced as more methanol was involved as the reactant in the esterification reaction. One interesting observation was that the reduction in FFA\% was more pronounce on RCFO compared to WCO. As the volume percentage of methanol to oil increased from $30 \% \mathrm{v} / \mathrm{v}$ to $45 \% \mathrm{v} / \mathrm{v}$, the FFA\% decreased from 2.34 to $0.70 \%$ for RCFO and 1.265 to $0.63 \%$ for WCO. In contrast, the conversion efficiency of RCFO increased from 52.54 to $85.80 \%$ for RCFO and 88.83 to $94.41 \%$ for WCO, for the same increment on the volume percentage of methanol to oil. Hence, $45 \% \mathrm{v} / \mathrm{v}$ was determined as the optimum volume percentage of methanol to oil for both RCFO and WCO.

\subsubsection{Effect of volume percentage of sulfuric acid to oil on FFA\%}

Figure 2 revealed that FFA\% of RCFO increased from 0.7 to $0.98 \%$ as the volume percentage of sulfuric acid to oil increased from 0.5 to $1 \% \mathrm{v} / \mathrm{v}$. A similar trend was observed for WCO in which the FFA\% increased from 0.63 to $0.96 \%$ for the same increment in volume percentage of sulfuric acid from 0.5 to $1 \% \mathrm{v} / \mathrm{v}$. The increased of the volume percentage of sulfuric acid to oil from 0.5 to $1 \% \mathrm{v} / \mathrm{v}$ in esterification favored the formation of methyl hydrogen sulfate and water as the by-product, where the excess sulfuric acid reacts with methanol [21]. Subsequently, more methanol was being consumed and the concentration of methanol decreased. Meanwhile, the concentration of water increased in the reaction system led to the direction of reaction equilibrium shifted backward which eventually reduced the formation of ester and increased the \%FFA, as shown in Eq. 5 [9]. On the other hand, the conversion efficiency of RCFO decreased from $85.80 \%$ to $80.12 \%$ as the volume percentage of sulfuric acid to oil increased from 0.5 to $1 \% \mathrm{v} / \mathrm{v}$. Meanwhile, the similar trend was observed for WCO in which the conversion efficiency dropped from 94.41 to $91.49 \%$. In short, the high volume percentage of sulfuric acid to oil of $1 \% \mathrm{v} / \mathrm{v}$ prevent the reduction in FFA $\%$. Hence, $0.5 \% \mathrm{v} / \mathrm{v}$ and $45 \% \mathrm{v} / \mathrm{v}$ were determined as the optimum volume percentage of sulfuric acid to oil and volume percentage of methanol to oil for RCFO and WCO, respectively, in which both oils were having FFA\% of approximately $0.7 \%$ that were suitable to be used as the feedstock in alkaline transesterification.

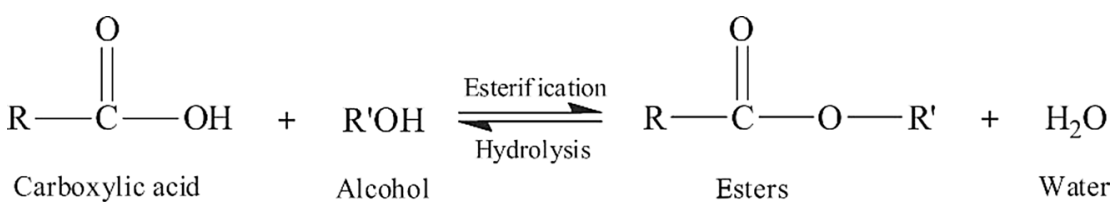

Fig. 2 Effect of volume percentage of sulfuric acid to oil on FFA \% and conversion efficiency (reaction temperature of $60^{\circ} \mathrm{C}$, reaction time of $2 \mathrm{~h}$, volume percentage of methanol to oil of $45 \% \mathrm{v} / \mathrm{v}$ )

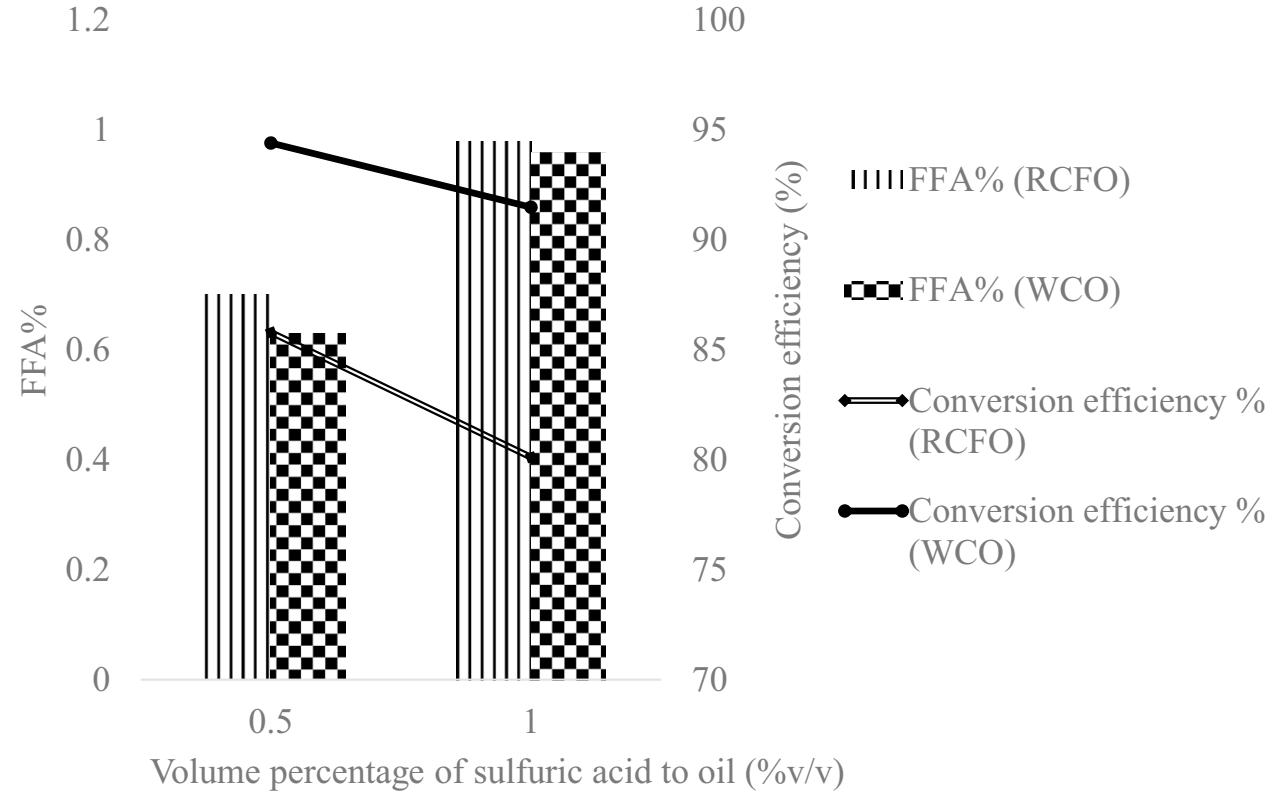

SN Applied Sciences A SPRINGER NATURE journa 


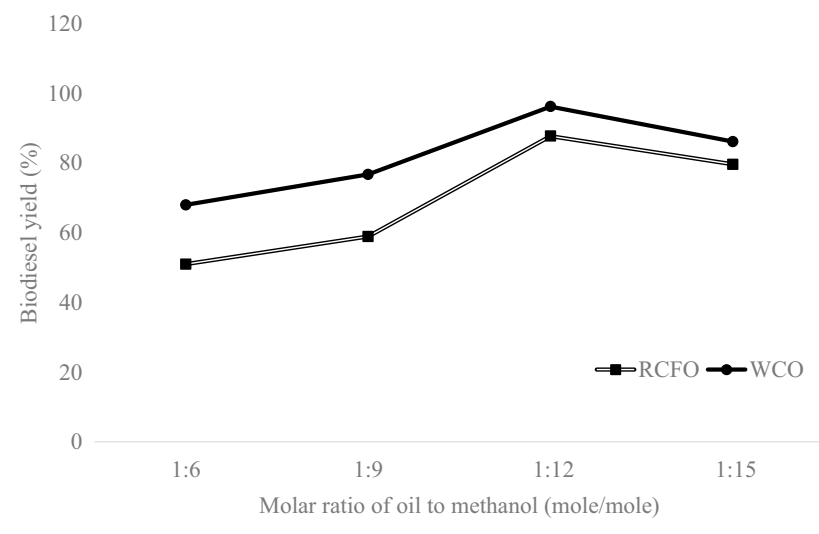

Fig. 3 Effect of molar ratio of oil to methanol on the yield of biodiesel (reaction temperature of $60^{\circ} \mathrm{C}$, catalyst loading of $1.5 \mathrm{wt} \%$, reaction time of $1 \mathrm{~h}$ )

\subsection{Alkaline transesterification}

\subsubsection{Effect of oil to methanol molar ratio on yield of FAME}

Figure 3 revealed that the yield of RCFO biodiesel increased from 48.12 to $87.77 \%$ as the molar ratio of oil to methanol was increased from $1: 6$ to $1: 12$. Similarly, the yield of WCO biodiesel increased from 65.36 to $96.23 \%$ as the molar ratio of oil to methanol was increased from 1:6 to $1: 12$. Molar ratio is one of the important factor affecting the conversion of oil in the transesterification reaction. Ideally, transesterification reaction requires $3 \mathrm{~mol}$ of alcohol to produce 1 mol of biodiesel. However, molar ratio should be higher than the stoichiometric ratio. This is because an excess of alcohol is required for the reaction to move forward and avoid the reversible reaction [22]. An optimum yield of biodiesel was obtained at a molar ratio of 1:12 which was $87.77 \%$ for RCFO and $96.23 \%$ for WCO. These findings could possibly imply that the interaction between oil and methanol molecules was enhanced and the yield of biodiesel increased as the molar ratio of oil to methanol increased up to 1:12. However, the increased in the molar ratio of oil to methanol from 1:12 to $1: 15$ led to a declined in the yield of biodiesel from 87.77 to $79.66 \%$ for RCFO and from 96.23 to $86.18 \%$ for WCO. This was probably due to the reverse transesterification reaction was promoted as the molecules of oil became the limiting molecules. Moreover, the high solubility of glycerol in ester phase at high concentration of methanol in the reaction system could also promoted the reverse reaction [23]. Hence, the optimum molar ratio of oil to methanol of 1:12 was selected for optimum yield of biodiesel for both RCFO and WCO.

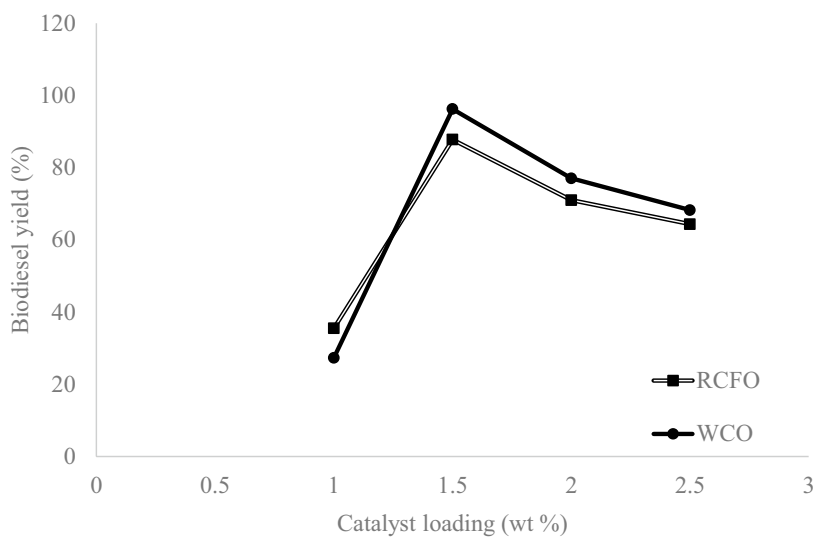

Fig. 4 Effect of catalyst loading on the yield of biodiesel (reaction temperature of $60{ }^{\circ} \mathrm{C}$, oil: methanol ratio of $1: 12$, reaction time of $1 \mathrm{~h})$

Table 3 Specific surface area of egg shells derived catalyst and commercial $\mathrm{CaO}$

\begin{tabular}{lll}
\hline Catalyst & $\begin{array}{l}\text { Specific surface } \\
\text { area }\left(\mathrm{m}^{2} / \mathrm{g}\right)\end{array}$ & Researchers \\
\hline Commercial CaO & 3.0022 & {$[24]$} \\
Egg shells derived catalyst & 3.7262 & {$[24]$} \\
Egg shells derived catalyst & 5.2090 & This study \\
\hline
\end{tabular}

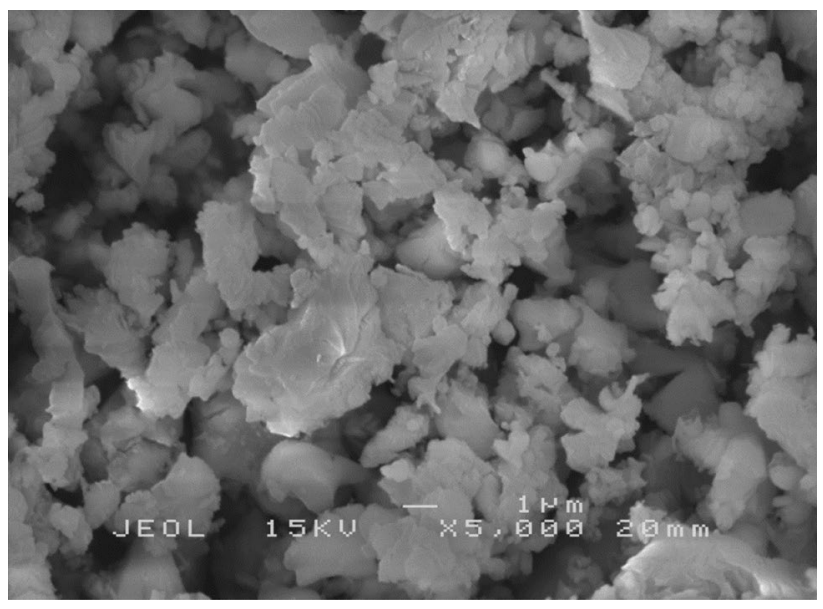

Fig. 5 SEM image of egg shells derived catalyst

\subsubsection{Effect of catalyst loading on yield of FAME}

Figure 4 showed the effect of catalyst loading on biodiesel yield. Initially, the yield of biodiesel obtained was very low for both RCFO and WCO which were $35.52 \%$ and $27.33 \%$, respectively at 1 wt\% catalyst loading. This was due to at a low catalyst loading of $1 \mathrm{wt} \%$, an insufficient 
amount of catalyst may lead to an incomplete reaction to obtain a high yield of biodiesel [24]. However, an optimum yield of biodiesel was obtained at $87.77 \%$ and $96.23 \%$ for RCFO and WCO, respectively, as the catalyst loading increased up to $1.5 \mathrm{wt} \%$. At this point, a sufficient amount of catalyst with the high specific surface area was supplied for the interaction between oil and methanol molecules to yield biodiesel. The BET analysis confirmed that the specific surface area of the egg shells derived catalyst was $5.2090 \mathrm{~m}^{2} / \mathrm{g}$ which was higher than the reported specific surface area of $3.7262 \mathrm{~m}^{2} / \mathrm{g}$ and $3.0022 \mathrm{~m}^{2} / \mathrm{g}$ for egg shells derived catalyst and commercial calcium oxide, respectively, as shown in Table 3. Besides that, the egg shells derived catalyst was noticed to be agglomerated as shown in the SEM image in Fig. 5 . The aggregation was due to the high specific surface area of the catalyst [25]. Further increased in catalyst loading to $2 \mathrm{wt} \%$ and $2.5 \%$ has resulted a dropped in the yield of biodiesel as observed for both RCFO and WCO. The yield of biodiesel was $64.35 \%$ for RCFO and $68.25 \%$ for WCO at $2.5 \mathrm{wt} \%$ of catalyst loading. This was due to increasing the amount of catalyst to more than $1.5 \mathrm{wt} \%$ led to a thicker solution which became too viscous and rose problems of mixing hence it did not increase the yield \% of biodiesel. At this point, there was mass transport limitation in which the transportation of reactants and products to and from the catalyst's active sites became the rate determining-step [26]. Hence, in short, under the condition of $1.5 \mathrm{wt} \%$ of catalyst loading, the optimum yield of biodiesel obtained was $87.77 \%$ and $96.23 \%$ for RCFO and WCO, respectively. The optimum yield obtained in this study was comparable to the findings reported by other researchers [27-30], as shown in Table 4. In addition, the optimum transesterification process conditions obtained were also equally reasonable. Therefore, the study has confirmed that RCFO and WFO were suitable to be the feedstocks in the production of biodiesel under the moderate optimum process conditions.

\subsection{Characterization of FAME and comparison with petroleum diesel and ASTM D6751}

Based on the optimization study, the optimum conditions for alkaline transesterification reaction catalyzed by egg shells derived catalyst was at $60^{\circ} \mathrm{C}, 60 \mathrm{~min}$, oil

Table 4 Comparisons of biodiesel yield obtained in this study and other researchers with the optimum transesterification process conditions

\begin{tabular}{lllllll}
\hline Optimum reaction condition & \multicolumn{2}{l}{ Researchers } & & & \\
\cline { 2 - 6 } & [27] & {$[28]$} & {$[29]$} & {$[30]$} & This study & This study \\
\hline Oil feedstock & Beef tallow & Pongam tree oil & Waste fish oil & Waste fish oil & RCFO & WCO \\
Alcohol & Methanol & Methanol & Methanol & Methanol & Methanol & Methanol \\
Catalyst & $\mathrm{KOH}$ & Synthesized & Synthesized & $\mathrm{KOH}$ & Synthesized CaO & Synthesized CaO \\
& & CaO from egg & CaO from crab & & from chicken egg & from chicken egg \\
& & shell & shell & & shell & shell \\
Molar ratio of oil to methanol & $1: 6$ & $1: 8$ & $1: 12$ & $1: 9$ & $1: 12$ & 1.12 \\
Catalyst loading (wt\%) & 1.5 & 2.5 & 2.5 & 1.0 & 1.5 & 60 \\
Temperature $\left({ }^{\circ} \mathrm{C}\right)$ & 60 & 65 & 65 & 60 & 60 & 60 \\
Time (min) & 60 & 60 & 90 & 60 & 60 & 60 \\
Yield of biodiesel (\%) & 96.40 & 95.00 & 96.60 & 99.10 & 87.77 & 96.23 \\
\hline
\end{tabular}

Table 5 Comparison of fuel properties of RCFO and WCO biodiesel with petroleum diesel and biodiesel standard ASTM D6751

\begin{tabular}{|c|c|c|c|c|c|c|c|}
\hline Property & Units & RCFO & RCFO biodiesel & WCO & WCO biodiesel & Petroleum diesel [31] & $\begin{array}{l}\text { Biodiesel standard } \\
\text { ASTM D6751 }\end{array}$ \\
\hline Color@ $27^{\circ} \mathrm{C}$ & - & Cloudy yellow & Clear golden & Dark brown & Golden yellow & Golden-dark brown & Golden-dark brown \\
\hline Physical state @ $27^{\circ} \mathrm{C}$ & - & Semi-solid & Liquid & Liquid & Liquid & Liquid & Liquid \\
\hline Density & $\mathrm{kg} / \mathrm{m}^{3}$ & 869.6 & 870.0 & 880.1 & 877.8 & $820.0-860.0$ & 874.6 \\
\hline FFA & $\%$ & 4.93 & 1.18 & 11.28 & 1.26 & - & - \\
\hline Calorific value & $\mathrm{MJ} / \mathrm{kg}$ & 36.32 & 40.75 & 23.60 & 41.47 & 45.50 & 37.27 \\
\hline $\begin{array}{l}\text { Kinematic viscosity @ } \\
40^{\circ} \mathrm{C}\end{array}$ & $\mathrm{mm}^{2} / \mathrm{s}$ & 43.6 & 6.0 & 35.4 & 2.3 & $2-4.5$ & $1.9-6.0$ \\
\hline
\end{tabular}


to methanol molar ratio of $1: 12$ and catalyst loading of $1.5 \mathrm{wt} \%$ to obtain the optimum yield of biodiesel which was $87.77 \%$ and $96.23 \%$, for RCFO and WCO, respectively. Table 5 revealed the physical and chemical characteristics of RCFO, RCFO biodiesel, WCO and WCO biodiesel in comparison with petroleum diesel [31] and biodiesel standard of ASTM D6751. The density of RCFO and WCO biodiesel were relatively higher than petroleum diesel but falls within the ASTM D6751 standard. High density of biodiesel has a short injection time to travel from injection pump to injector in engine [32]. Thus, RCFO and WCO biodiesel exhibited an extraordinary property in terms of density as compared to petroleum diesel. On the other hand, it was observed that the calorific value of raw oils was lesser than biodiesel. This was because of the presence of longer carbon chain of the methyl ester in biodiesel which gives higher calorific value [33]. Comparing the RCFO biodiesel and WCO biodiesel with petroleum diesel, the calorific value of both biodiesels of $40.75 \mathrm{MJ} / \mathrm{kg}$ and $41.47 \mathrm{MJ} / \mathrm{kg}$, respectively, were lesser than the petroleum diesel of $45.5 \mathrm{MJ} / \mathrm{kg}$. Generally, carbon and hydrogen are the sources of thermal energy in fuel. However, the oxygen content in biodiesel is higher than petroleum diesel [23]. In other words, the content of carbon and hydrogen in biodiesel is lower than petroleum diesel that led to a low source of thermal energy and calorific value of biodiesel. On the other hand, the viscosity of RCFO and WCO biodiesel of $6.00 \mathrm{~mm}^{2} / \mathrm{s}$ and $2.28 \mathrm{~mm}^{2} / \mathrm{s}$ at $40{ }^{\circ} \mathrm{C}$, respectively, were also meet the specification of petroleum diesel and ASTM D6751 standards. Hence, both biodiesels were considered suitable for the application as a fuel for combustion in engines based on the physiochemical properties.

\section{Conclusion}

This study has successfully demonstrated the utilization of waste materials such as fish waste, WCO and waste chicken egg shells as the feedstocks in the production of biodiesel. RCFO was extracted from RCFW with the recovery of oil of approximately $18 \mathrm{wt} \%$ and the egg shells derived catalyst showed high specific surface area and high catalytic activity towards the production of biodiesel, after calcination at $900^{\circ} \mathrm{C}$ and $1 \mathrm{~h}$. The high percentage of FFAs in RCFO and WCO were successfully reduced to less than $1 \%$, through sulfuric acid esterification under the optimum conditions of $45 \% \mathrm{v} / \mathrm{v}$ of methanol to oil and $0.5 \% \mathrm{v} / \mathrm{v}$ of sulfuric acid to oil, for $2 \mathrm{~h}$ at $60^{\circ} \mathrm{C}$. In the alkaline transesterification, an optimum yield of biodiesel of $87.77 \%$ for RCFO and $96.23 \%$ for WCO were obtained at oil to methanol molar ratio of $1: 12,1.5$ wt $\%$ of catalyst loading for reaction temperature at $60{ }^{\circ} \mathrm{C}$ and $60 \mathrm{~min}$. The properties of RCFO biodiesel and WCO biodiesel were characterized and it met the biodiesel standard of ASTM D6751. Hence, RCFO biodiesel and WCO biodiesel were identified as an alternative feedstock for biodiesel production. The utilization of wastes materials as the feedstocks are economical and sustainable that could reduce the production cost of biodiesel.

Acknowledgements The authors gratefully acknowledge the Department of Chemical Engineering, School of Science and Engineering, Manipal International University (MIU), Nilai for the financial support given.

\section{Compliance with ethical standards}

Conflict of interest The authors declare that they have no conflict of interest.

\section{References}

1. Vyas A, Verma J, Subrahmanyam N (2011) Effects of molar ratio, alkali catalyst concentration and temperature on transesterification of jatropha oil with methanol under ultrasonic irradiation. Adv Chem Eng Sci 01(02):45-50. https://doi. org/10.4236/aces.2011.12008

2. Yang Z, Hollebone BP et al (2015) A preliminary study for the photolysis behavior of biodiesel and its blends with petroleum oil in simulated freshwater. Fuel 139:248-256. https:// doi.org/10.1016/j.fuel.2014.08.061

3. Banapurmath NR, Tiwari PG, Hosmath RS (2008) Performance and emission characteristics of a DI compression ignition engine operated on Honge, Jatropha and Sesame oil methyl esters. Renew Energy 33:1982-1988. https://doi.org/10.1016/j. renene.2007.11.012

4. Banković-Ilić IB, Stojković IJ, Stamenkovic OS, Velijkovic VB, Hung YT (2014) Waste animal fats as feedstocks for biodiesel production. Renew Sustain Energy Rev 32(2014):238-254

5. Chukwuezie OC, Nwakuba NR, Asoegwu SN, Nwaigwe KN (2017) Cetane number effect on engine performance and gas emission: a review. Am J Eng Res (AJER) 6(1):56-67

6. Phuong NT, Oanh DTH (2010) Striped catfish aquaculture in Vietnam: a decade of unprecedented development. In: De Silva SS, Davy FB (eds) Success stories in Asian aquaculture. Springer, Dordrecht. https://doi. org/10.1007/978-90-481-3087-0_7

7. Yuvaraj D, Bharathiraja B, Rithika J, Dhanasree S, Ezhilarasi V, Lavanya A, Praveenkumar R (2016) Production of biofuels from fish wastes: an overview. Biofuels. https://doi. org/10.1080/17597269.2016.1231951

8. Jayasinghe P, Adeoti I, Hawboldt K (2013) A study of process optimization of extraction of oil from fish waste for use as a low-grade fuel. J Am Oil Chem Soc 90(12):1903-1915. https:// doi.org/10.1007/s11746-013-2321-1

9. Saha R, Goud V (2014) Ultrasound assisted transesterification of high free fatty acids karanja oil using heterogeneous base catalysts. Biomass Convers Biorefinery 5(2):195-207. https:// doi.org/10.1007/s13399-014-0133-7

10. Otadi M, Shahraki A, Goharrokhi M, Bandarchian F (2011) Reduction of free fatty acids of waste oil by acid-catalyzed 
esterification. Procedia Eng 18:168-174. https://doi. org/10.1016/j.proeng.2011.11.027

11. Ibeto C, Ofoefule A, Ezeugwu H (2011) Fuel quality assessment of biodiesel produced from groundnut oil (Arachis hypogea) and its blend with petroleum diesel. Am J Food Technol 6(9):798-803. https://doi.org/10.3923/ajft.2011.798.803

12. García-Moreno P, Khanum M, Guadix A, Guadix E (2014) Optimization of biodiesel production from waste fish oil. Renew Energy 68:618-624. https://doi.org/10.1016/j.renene.2014.03.014

13. Ruan D, Chen Z, Wang K, Chen Y, Yang F (2014) Physical property prediction for waste cooking oil biodiesel. Open Fuels Energy Sci J 7(1):62-68. https://doi.org/10.2174/1876973X01407010062

14. Yee KF, Wu JCS, Lee KT (2011) A green catalyst for biodiesel production from Jatropha oil: optimization study. Biomass and Bioernergy 35(5):1739-1746. https://doi.org/10.1016/j. biombioe.2011.01.017

15. University, I (2018) Fat and why it matters. http://www.india na.edu/ oso/Fat/SolidNLiquid.html. Accessed 10 Oct 2018

16. Muhamad NA, Mohamad J (2012) Fatty acids composition of selected Malaysian fishes. Sains Malays 41(1):81-94

17. Abidin S, Patel D, Saha B (2013) Quantitative analysis of fatty acids composition in the used cooking oil (UCO) by gas chromatography-mass spectrometry (GC-MS). Can J Chem Eng 91(12):1896-1903. https://doi.org/10.1002/cjce.21848

18. De Oliveira D, Minozzo M, Licodiedoff S, Waszczynskyj N (2016) Physicochemical and sensory characterization of refined and deodorized tuna (Thunnus albacares) by-product oil obtained by enzymatic hydrolysis. Food Chem 207:187-194. https://doi. org/10.1016/j.foodchem.2016.03.069

19. Yee KF, Lee KT, Ceccato R, Abdullah AZ (2011) Production of biodiesel from Jatropha curcas $\mathrm{L}$. oil catalyzed by $\mathrm{SO}_{4}{ }^{2-} / \mathrm{ZrO}_{2}$ catalyst: effect of interaction between process variables. Bioresour Technol 102(5):4285-4289. https://doi.org/10.1016/j.biort ech.2010.12.048

20. Kaushik N, Kumar K, Kumar S (2007) Potential of Jatropha curcas for biofuels. J Biobased Mater Bioenergy 1(3):301-314. https:// doi.org/10.1166/jbmb.2007.002

21. Chai M, Tu QS, Lu MM, Yang YJ (2014) Esterification pretreatment of free fatty acid in biodiesel production, from laboratory to industry. Fuel Process Technol 125:106-113. https://doi. org/10.1016/j.fuproc.2014.03.025

22. Elkady MF, Zaatout Ahmed, Balbaa Ola (2015) Production of biodiesel from waste vegetable oil via KM micromixer. J Chem 2015:1-9. https://doi.org/10.1155/2015/630168
23. Ayetor GK, Sunnu A, Parbey J (2015) Effect of biodiesel production parameters on viscosity and yield of metgyl esters: Jatropha curcas, Elaeis guineensis and Cocos nucifera. Alex Eng J 54(4):1285-1290. https://doi.org/10.1016/j.aej.2015.09.011

24. Niju S, Meera KM, Begum S, Anantharaman N (2014) Modification of egg shell and its application in biodiesel production. J Saudi Chem Soc 18(5):702-706. https://doi.org/10.1016/j. jscs.2014.02.010

25. Pandit P, Fulekar M (2017) Egg shell waste as heterogeneous nanocatalyst for biodiesel production: optimized by response surface methodology. J Environ Manag 198:319-329. https:// doi.org/10.1016/j.jenvman.2017.04.100

26. Wei Z, Xu C, Li B (2009) Application of waste eggshell as low-cost solid catalyst for biodiesel production. Bioresour Technol 100(11):2883-2885. https://doi.org/10.1016/j.biort ech.2008.12.039

27. Singh SP, Singh D (2010) Biodiesel production through the use of different sources and characterization of oils and their esters as the substitute of diesel: a review. Renew Sustain Energy Rev 14(1):200-216. https://doi.org/10.1016/j.rser.2009.07.017

28. Sharma YC, Singh B, Korstad J (2010) Application of an efficient nonconventional heterogeneous catalyst for biodiesel synthesis from Pongamia pinnata oil. Energy Fuels 24(5):3223-3231. https ://doi.org/10.1021/ef901514a

29. Madhu D, Arora R, Sahani S, Singh V, Sharma Y (2017) Synthesis of high-quality biodiesel using feedstock and catalyst derived from fish wastes. J Agric Food Chem 65(10):2100-2109. https:// doi.org/10.1021/acs.jafc.6b05608

30. Kara K, Ouanji F, El Lotfi M, El Mahi M, Kacimi M, Ziyad M (2018) Biodiesel production from waste fish oil with high free fatty acid content from Moroccan fish-processing industries. Egypt J Pet 27(2):249-255. https://doi.org/10.1016/j.ejpe.2017.07.010

31. Joseph C, Chidozie V, Obioma U, Christopher C, Emeka G (2014) Potentials of non-edible Abrus precatorius seed oil towards biodiesel production. Afr J Biotechnol 13(44):4226-4235. https:// doi.org/10.5897/ajb2014.13979

32. Caresana F (2011) Impact of biodiesel bulk modulus on injection pressure and injection timing. The effect of residual pressure. Fuel 90(2):477-485. https://doi.org/10.1016/j.fuel.2010.10.005

33. Oliveira LE, Da Silva MLCP (2013) Comparative study of calorific value of rapeseed, soybean, jatropha curcas and crambe biodiesel. Renew Energy Power Qual J 1(11):679-682. https://doi. org/10.24084/repqj11.411 